\title{
Dual augmentation for aerobic bioremediation of MTBE and TCE pollution in heavy metal-contaminated soil
}

\author{
V. C. Fernandes, J. T. Albergaria, T. Oliva-Teles, C. Delerue-Matos, P. De Marco
}

\begin{abstract}
In this work we isolated from soil and characterized several bacterial strains capable of either resisting high concentrations of heavy metals

$\left(\mathrm{Cd}^{2 ?}\right.$ or $\mathrm{Hg}^{2}$ or $\left.\mathrm{Pb}^{2 ?}\right)$ or degrading the common soil and groundwater pollutants MTBE (methyl-tertbutyl ether) or TCE (trichloroethylene). We then used soil microcosms exposed to MTBE $(50 \mathrm{mg} / \mathrm{l})$ or TCE $(50 \mathrm{mg} / \mathrm{l})$ in the presence of one heavy metal $(\mathrm{Cd} 10$ ppm or $\mathrm{Hg} 5 \mathrm{ppm}$ or $\mathrm{Pb} 50$ or $100 \mathrm{ppm}$ ) and two bacterial isolates at a time, a degrader plus a metalresistant strain. Some of these two-membered consortia showed degradation efficiencies well higher (49-182\% higher) than those expected under the conditions employed, demonstrating the occurrence of a synergetic relationship between the strains used. Our results show the efficacy of the dual augmentation strategy for MTBE and TCE bioremediation in the presence of heavy metals.
\end{abstract}

Keywords Bioremediation - Soil - Heavy metal $\cdot \mathrm{TCE} \cdot \mathrm{MTBE} \cdot \mathrm{Cadmium} \cdot \mathrm{Lead} \cdot$ Mercury

\section{Introduction}

Remediation of sites co-contaminated with organic and metal pollutants is a complex problem, as the two components often must be treated differently. A high proportion of hazardous waste sites are co-contaminated with organic and metal pollutants (Sandrin and Maier 2003).

MTBE (methyl-tert-butyl ether) is the most widely used fuel ether and is very soluble in water $(40 \mathrm{~g} / \mathrm{l})$ and thus able to migrate easily to groundwater producing large contamination plumes in impacted aquifers (USEPA 1997). It is known that MTBE can be degraded by co-metabolism as was observed during growth of various microorganisms on different carbon substrates (Brusseau et al. 1990; Bowman et al. 1993; Fayolle et al. 2003).

TCE (trichloroethylene) is used mainly as a solvent to remove grease from metal parts, namely for cleaning aircrafts at air-force bases, but it is also an ingredient in adhesives, paint removers, typewriter correction fluids and spot removers. As a pollutant, it has been found in underground aquifers, many surface waters and soils as a result of its use and improper disposal (ATSDR 2003). In aerobic conditions TCE disappearance was related to the cometabolic activity of local microflora: methanotrophs using either type of methane monooxygenase (DiSpirito et al. 1991) or aromatic-degraders expressing enzymes such as toluene monooxygenase (Shields et al. 1995). 
For clean up of groundwater and soils contaminated by chlorinated solvents natural attenuation may be inadequate and bioaugmentation may be the only practical option (Aulenta et al. 2005; Olaniran et al. 2006; Adebusoye et al. 2007).

Co-contaminated soils are considered difficult to remediate because of the mixed nature of the contaminants. Many microorganisms are known to degrade a variety of organics, and likewise a number of metal-resistant microorganisms are known to detoxify metals such as lead, mercury or cadmium. Some works have analyzed the possibility of remediation of organic pollution in heavy metalcontaminated soils (Roane et al. 2001; Lee et al. 2006).

To date, several studies have shown the acute effects of heavy metals on microbial communities. Results from these studies indicated that heavy metal amendments have a negative impact, resulting in severe reduction of metabolic activity, microbial biomass and bacterial abundance (Sandrin and Maier 2003). The inhibition of the degradation of organic pollutants is directly related to heavy metal concentrations. Subsequent shifts in the microbial community toward a more metal-tolerant or metalresistant population has also been observed with increasing inputs of heavy metals (Sandrin and Maier 2003). Metals may inhibit remediation through interaction with the enzymes directly involved in biodegradation or through interaction with general microbial metabolism (Sandrin and Maier 2003).

Metal inhibition has also been observed in metalcontaminated soils systems. For example, cadmium added at levels of $60 \mathrm{mg}$ total cadmium $/ \mathrm{kg}$ was found to inhibit biodegradation of 2,4-dichlorophenoxyacetic acid (2,4-D) in a soil system inoculated with the 2,4-D-degrader Ralstonia eutropha strain JMP134. For rapid degradation of 2,4-D to be achieved, it was necessary to co-inoculate str. JMP134 and a cadmium-resistant isolate, Pseudomonas H1, which accumulates cadmium intracellularly (Roane et al. 2001). These results suggest that in the presence of a toxic metal, inoculation with metal-resistant microorganisms that reduce bioavailable metal concentrations via sequestration will foster the increase of biodegradation. In another study, in order to reduce the cadmium potentially available to plants, soil bioaugmentation was performed by using Bacillus sp. (Je'zéquel et al. 2005). A more recent example (Lee et al. 2006) involved recombinant rhizobacteria (Pseudomonas and Rhizobium) expressing a cysteinrich peptide at the cell surface and thus improving their TCE degradation in the presence of $\mathrm{Cd}$.

In this study, the effect of soil bioaugmentation with natural bacterial strains on the biodegradation of TCE or MTBE was investigated in order to assess the possibility to improve aerobic remediation of these compounds in contaminated soils. The approach used in this study was to coinoculate a metal-detoxifying population with an organic-degrading population that cooperatively functioned to remediate organic pollution in such co-contaminated systems.

\section{Material and methods}

Enrichment and growth of strains

All enrichments were performed in tryptic soy broth (TSB) at $26^{\circ} \mathrm{C}$ with shaking and by sub-culturing in TSB with growing concentrations of metals (5$1,500 \mathrm{mg} / \mathrm{l} \mathrm{Cd}^{2}$ or $5-30 \mathrm{mg} / \mathrm{l} \mathrm{Hg}^{2}$ or $5-1,000 \mathrm{mg} / \mathrm{l}$ $\mathrm{Pb}^{2 ?}$ ). All strains were tested for growth on solid medium with a $\mathrm{C}_{1}$ compound (methanol), organic acid (lactate) or glycerol in minimal medium MinE plus $16 \mathrm{~g} / \mathrm{l}$ agar as described in Kelly et al. (1994), buffered with $10 \mathrm{mM}$ phosphate $(\mathrm{pH}$ 6.8). When metals were used, minimal medium MinE was buffered with $100 \mathrm{mM}$ MOPS $\mathrm{pH} 7$ to avoid metal precipitation with phosphate. The original inocula were spoonfuls of soil samples obtained from polluted soils collected in the vicinity of the Estarreja Channel of Ria de Aveiro, northern Portugal. This channel has received mercury-rich effluent of a chloralkali industrial plant since the 1950s and the soil samples were contaminated with levels of $\mathrm{Hg}$, $\mathrm{Zn}, \mathrm{Cd}$ and $\mathrm{Pb}$ above the EU limits for agricultural soils (Commission of the European Communities 1986).

Five of the bacterial strains used in the bioaugmentation experiments had been isolated previously using enrichment techniques from pristine or contaminated soil samples, as described in De Marco et al. (2004). The remaining 12, the VF series, were obtained in this study. Resistance to the presence of heavy metals was assayed for all the isolates used in this study by testing growth on solidified MinE medium at increasing concentrations of $\mathrm{CdCl}_{2}$, or 
$\mathrm{HgCl}_{2}$ or $\mathrm{PbCl}_{2}$ (Sigma-Aldrich). Data on all the strains are shown in Table 1.

Microcosm inocula were grown aerobically at $26^{\circ} \mathrm{C}$ in minimal medium MinE buffered with $10 \mathrm{mM}$ phosphate ( $\mathrm{pH}$ 6.8) and supplemented with $0.1 \%$ yeast extract. The carbon sources used for the study were lactate or glycerol. Cultures were harvested by centrifugation and resuspended in the same medium to an optical density $(600 \mathrm{~nm})$ of $1.5-2$.

The strains tested in this study are listed in Table 1.

\section{Classification of the isolates}

DNA was extracted from ca. $300 \mathrm{mg}$ of wet cell pellet of each isolate by resuspending in 5011 s.d.w. and immersing in boiling water for $10 \mathrm{~min}$. After centrifuging, 1-2 11 of the supernatant were used as template in PCR reactions using universal $16 \mathrm{~S}$ rDNA primers f27 and r1492 (Lane 1991). The amplicons obtained were cloned into plasmid vector pGEM $^{\circledR} \mathrm{T}$ EASY (Promega) and partially sequenced using vector-based primer M13rev which yielded reads of
500-700 bps. The sequences obtained were used in BLAST searches of the non-redundant NCBI database (www.ncbi.nlm.nih.gov/Blast.cgi) in order to obtain an approximate classification of each strain.

Composition of the soil

Microcosms were set up using sieved (10 mesh) commercial garden substrate. The soil thus obtained was analyzed and the results were: $\mathrm{pH}=5.75,55 \%$ organic matter, $61 \%$ humidity, $9.86 \%$ porosity and particle density was $0.352 \mathrm{~g} / \mathrm{ml}$.

\section{Soil microcosms}

Each microcosm contained $25 \mathrm{~g}$ of soil inoculated with $15 \mathrm{ml}$ of the singular bacterial cultures at $\mathrm{OD}_{600}$ of 1.5-2. When combinations of two strains were used, $7.5 \mathrm{ml}$ of each culture were employed. When heavy metals were used, each salt $\left(\mathrm{CdCl}_{2}\right.$ or $\mathrm{HgCl}_{2}$ or $\mathrm{Pb}\left(\mathrm{NO}_{3}\right)_{2}$ - Sigma-Aldrich) was dissolved in a maximum volume of 15011 sterile distilled water and

Table 1 Metal resistance levels and pollutant degradation efficiency of the strains used in this study

\begin{tabular}{|c|c|c|c|c|c|c|}
\hline $\begin{array}{l}\text { Trait } \\
\text { strain }\end{array}$ & $\begin{array}{l}\text { Approximate classification } \\
\text { (DNA seq. identity) }\end{array}$ & $\begin{array}{l}\text { Cadmium } \\
(\mathrm{Cd}) / \mathrm{ppm}^{\mathrm{d}}\end{array}$ & $\begin{array}{l}\text { Mercury } \\
(\mathrm{Hg}) / \mathrm{ppm}^{\mathrm{d}}\end{array}$ & $\begin{array}{l}\text { Lead } \\
(\mathrm{Pb}) / \mathrm{ppm}^{\mathrm{d}}\end{array}$ & $\begin{array}{l}\text { Degradation } \\
\text { of } \operatorname{TCE}^{\mathrm{e}}(\%)\end{array}$ & $\begin{array}{l}\text { Degradation } \\
\text { of } \operatorname{MTBE}^{\mathrm{e}}(\%)\end{array}$ \\
\hline PM1 & Methylobacterium $^{\mathrm{a}}$ & 500 & 0 & 250 & 16.15 & 23.9 \\
\hline Mi1 & Methylobacterium $^{\mathrm{a}}$ & 500 & 1 & 400 & 29.46 & 40.14 \\
\hline F5.4 & Methylobacterium $^{\mathrm{a}}$ & 800 & 15 & 300 & 33.67 & 6.93 \\
\hline $\mathrm{EHg} 5$ & Methyloversatilis ${ }^{\mathrm{a}, \mathrm{b}}$ & 40 & 5 & 500 & 25.92 & 21.15 \\
\hline $\mathrm{EHg} 7$ & Methylophilus $^{\mathrm{a}}$ & 40 & 0 & 200 & 31.80 & 0 \\
\hline VF1 & Alcaligenes faecalis (99\%) & 700 & 1 & 300 & 0 & 0 \\
\hline VF2 & Alcaligenes faecalis (99\%) & 700 & 5 & 300 & 15.78 & 22.84 \\
\hline VF3 & Methylobacterium $^{\mathrm{c}}$ & 1,500 & 5 & 100 & 5.48 & 39.93 \\
\hline VF4 & Methylobacterium ${ }^{\mathrm{c}}$ & 1,000 & 5 & 100 & 3.90 & 0 \\
\hline VF5 & Ralstonia gilardii (99\%) & 20 & 0 & 50 & 0 & 24.95 \\
\hline VF6 & Micrococcus luteus (99\%) & 50 & 0 & 100 & 4.90 & 7.55 \\
\hline VF7 & Bacillus cereus $(99 \%)$ & 100 & 1 & 100 & 2.61 & 25.96 \\
\hline VF8 & Bacillus cereus $(100 \%)$ & 100 & 1 & 100 & 0 & 3.58 \\
\hline VF9 & Ralstonia taiwanensis (99\%) & 100 & 0 & 100 & 11.13 & 0 \\
\hline VF10 & Brevundimonas diminuta (99\%) & 20 & 0 & 100 & 0 & 0 \\
\hline VF11 & Methylobacterium $^{\mathrm{c}}$ & 700 & 5 & 100 & 5.47 & 0 \\
\hline VF12 & Methylobacterium $^{\mathrm{c}}$ & 700 & 10 & 100 & 2.57 & 6.03 \\
\hline
\end{tabular}

VF strains are new isolates obtained in this study. ${ }^{a}$ Strains obtained earlier as described in De Marco et al. (2004) or ${ }^{b}$ Kalyuzhnaya et al. (2006); " phenotypical classification (see "Material and methods"); ' $m a x i m u m$ concentration of metal withstood by the strain in solid medium; "these percentages of degradation were measured in microcosms in all identical to those described in the "Material and methods". The results were obtained after two weeks of incubation 
added to the microcosm together with the bacterial inoculum. Final metal concentrations were 1-20 ppm for $\mathrm{Cd}, 1-10 \mathrm{ppm}$ for $\mathrm{Hg}$ and $50-100 \mathrm{ppm}$ for $\mathrm{Pb}$. Inoculation was followed by vigorous soil mixing. Incubation was performed in $500 \mathrm{ml}$ flasks stoppered with Teflon valves (Mininert $^{\mathrm{TM}}, \mathrm{VICI}^{\circledR}$, Valco instruments) to prevent losses due to volatilization. The headspace in each flask was made up of approximately $450 \mathrm{ml}$ of air. In parallel, soil controls inoculated with sterile minimal medium MinE were monitored. The stoppered soil microcosms were injected through the septa with $22.5 \mathrm{mg}$ of the organic compounds (TCE or MTBE; corresponding to a final headspace concentration of $50 \mathrm{mg} / \mathrm{l}$ ) and incubated at $20^{\circ} \mathrm{C}$. The kinetic seen in control microcosms without bacterial inoculation showed a clear initial drop in the concentrations of the volatile organics for the first half to $1 \mathrm{~h}$ likely due to equilibration between the gas and solid phases, followed by a stabilization that lasted for the 15 days of the span of these tests (data not shown). Although the soil used was not sterile nor was any of the flasks autoclaved, the uninoculated microcosms showed a remarkable absence of degradation activity with either TCE or MTBE. Thus, the base-line concentrations of the organics were determined $30 \mathrm{~min}$ after injection. This initial adjustment corresponded to a drop of $20-40 \%$ of the initial headspace concentration. The headspaces of the microcosms were then regularly sampled and analyzed by GCFID to determine the rates of degradation of the pollutant. Concentrations of headspace TCE and MTBE were measured three times each week, typically at days $0,3,5,7,10,12$ and 15 , for a total of 15 days. Headspace samples (in duplicate) were extracted using a gas-tight syringe through the septum. Each soil experiment was performed in triplicate. The results shown in this study (Figs. 1, 2) are already net results at day 15 of incubation, where the background disappearance of pollutant measured in negative controls has been subtracted.

\section{Analytical method}

TCE and MTBE degradation in the different microcosms was monitored by headspace samples analysis in a gas chromatograph (GC) (Achten and Püttmann 2001). Using a gastight syringe, $1 \mathrm{ml}$ headspace samples were injected into a gas chromatograph equipped with a flame ionization detector (FID) (Chrompack CP
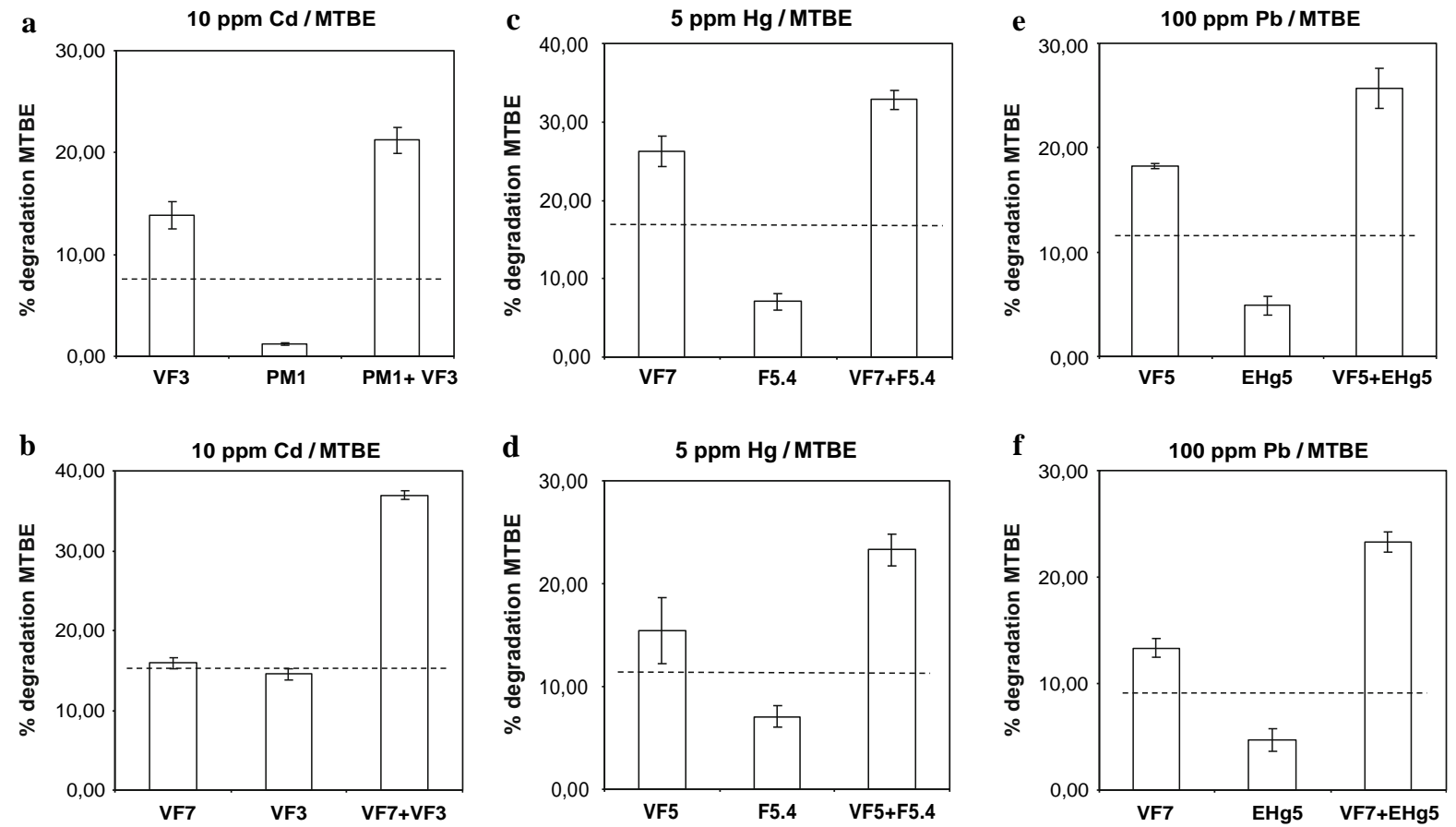

Fig. 1 Degradation of MTBE in the presence of the heavy metals ( $\mathrm{Cd}, \mathrm{Hg}$, or $\mathrm{Pb}$ ) by the doubly inoculated microcosms, as indicated. The dashed line shows the expected degradation level (mean of the two single strains) 

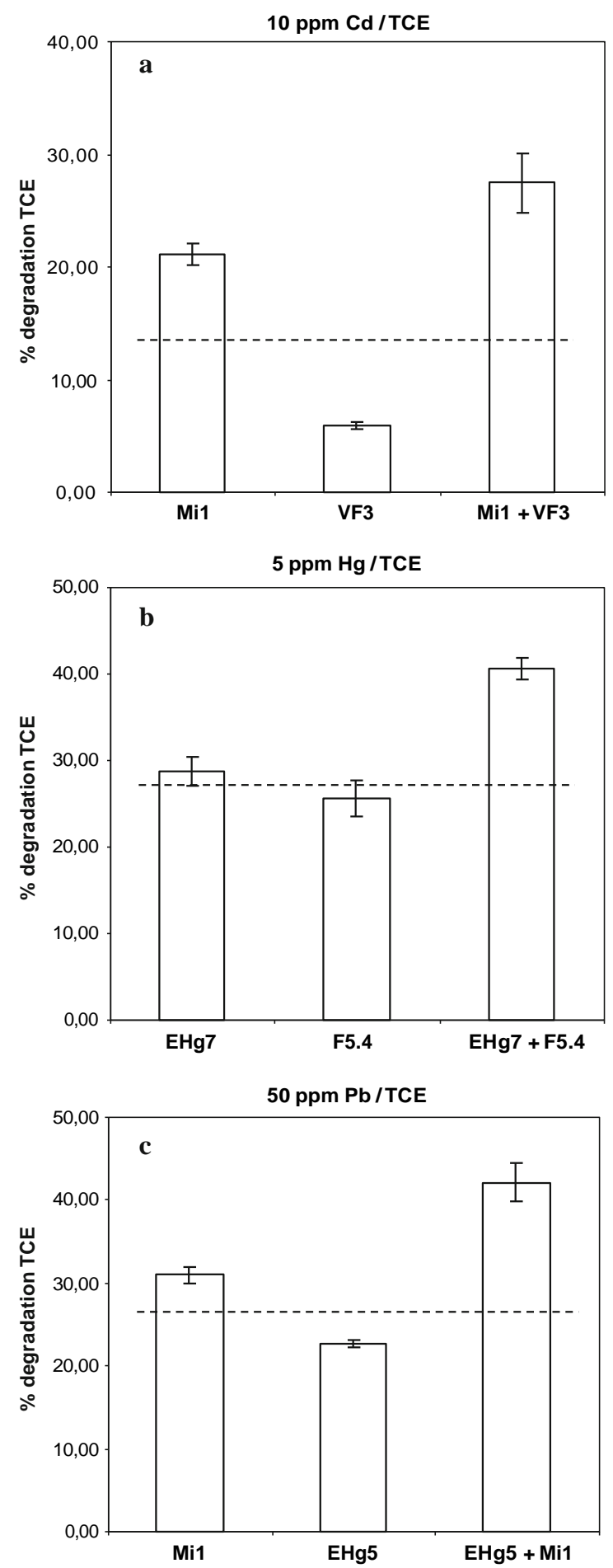

Fig. 2 Degradation of TCE in the presence of the heavy metals $(\mathrm{Cd}, \mathrm{Hg}$, or $\mathrm{Pb})$ by the doubly inoculated microcosms, as indicated. The dashed line shows the expected degradation level (mean of the two single strains)
9000). The GC column (CP-Wax $52 \mathrm{CB}, 25 \mathrm{~m}$ by $0.53 \mathrm{~mm}$, Chrompack) was run at isothermic temperature $\left(200^{\circ} \mathrm{C}\right)$. The detector and injector temperatures were 325 and $275^{\circ} \mathrm{C}$, respectively. $\mathrm{N}_{2}$ served as carrier gas at a flow rate of $7 \mathrm{ml} / \mathrm{min}$.

To obtain concentration standards, five $200 \mathrm{ml}$ flasks were used. Each of these flasks was sealed with a gastight Mininert ${ }^{\mathrm{TM}}$ valve. Different amounts of MTBE (Fluka, assay C 99.5\%) or TCE (Fluka, assay $\mathrm{C} 99.5 \%$ ) between 1 and 2011 were injected into the flasks using a gastight syringe, resulting in five different calibration standards for each compound in the appropriate range of 5-50 $\mathrm{mg} / \mathrm{l}$. Sampling was performed after $15 \mathrm{~min}$, when all the liquid compound added was vaporized.

For the calibration curves, $1 \mathrm{ml}$ samples were taken from each flask and injected directly into the GC-FID. All these samples were taken in triplicate. The correlation coefficient of the calibration curves for both TCE and MTBE was 0.996. The limits of detection and quantification were 3.95 and $13.16 \mathrm{mg} /$ 1 for MTBE and 4.10 and $13.68 \mathrm{mg} / \mathrm{l}$ for TCE.

\section{Results}

Selection of strains

Strains PM1, Mi1, F5.4, EHg5 and EHg7 were selected from the culture collection obtained during a previous study on robust soil methylotrophs (De Marco et al. 2004). The 12 strains of the VF series were obtained in new enrichments as described in the "Material and methods". VF3, VF4, VF11 and VF12 had all the typical characteristics of the genus Methylobacterium (pink colonies, facultative growth on methanol and/or methylamine, Gram negative rods). For this reason, they were empirically classified as Methylobacterium strains. The other VF strains were preliminarily classified based on their $16 \mathrm{~S}$ rDNA sequences and the results are summarized in Table 1. It is clear that the enrichment conditions favored Gram-negatives, which are the most abundant group in the newly obtained collection. However, two Bacillus strains and aicrococcus were also present.

All the strains listed in Table 1 were tested for their resistance to the three chosen heavy metals. The highest concentrations tolerated were $1,500 \mathrm{ppm}$ 
(mg/l) of Cd (by str. VF3), 500 ppm of $\mathrm{Pb}$ (by str. EHg5) and 15 ppm of $\mathrm{Hg}$ (by str. F5.4).

A second round of selection was performed based on the strains' ability to degrade MTBE or TCE in microcosm conditions. As can be seen in Table 1, the best degraders of MTBE were, in descending order, strains Mi1, VF3, VF7 and VF5. As for TCE, strains $\mathrm{F} 5.4, \mathrm{EHg}$, Mi1 and $\mathrm{EHg} 5$ were the best performers. Strains VF1, VF2, VF10, VF11 and VF12 displayed erratic growth in liquid medium and due to this reason were eliminated from this study. All strains tested showed a decreasing capacity of MTBE or TCE removal with increasing concentrations of heavy metals, which clearly proves that the action of the bacterial biomass on the organic pollutants was due to biological activity.

Preliminary microcosm experiments (results not shown) were performed with the best degraders and increasing concentrations of metals $(\mathrm{Cd} \mathrm{1,} \mathrm{5,} \mathrm{10,}$ 20 ppm; Hg 1, 5, 10 ppm; Pb 50 and 100 ppm). The degradation rates of the organic pollutants dropped dramatically (80-90\%) at $20 \mathrm{ppm} \mathrm{Cd}, 10 \mathrm{ppm} \mathrm{Hg}$ or $100 \mathrm{ppm} \mathrm{Pb}$, so the next lower concentration for each metal was chosen.

Best degraders were then coupled to most resistant strains for each metal and the analyses repeated in the same manner. Some of the couples (e.g. Mi1 ? VF12 with TCE ? Hg 5 ppm or with MTBE and $\mathrm{Hg}$ $5 \mathrm{ppm}$ ) showed combined degradation levels approximate to the mean of the values of the two single strains, as expected. Other pairs showed values below the mean (e.g. EHg7 ? VF3 with TCE and Cd, $-28 \%$ or VF3 ? Mi1 with MTBE and Cd, $-25 \%$ ). A few other combinations showed higher performances when taken together than singularly: of these cases we describe below the best examples.

\section{MTBE degradation tests}

In the experiments with MTBE and in the presence of metals, strains VF3, VF7 and VF5 were chosen as degraders while strains PM1, VF3, F5.4 and EHg5 were used as resistant members of the consortia (PM1 or VF3 for Cd; F5.4 for Hg; EHg5 for Pb). Strain VF3 was actually used in both roles due to its good performance in degrading MTBE and its resistance to Cd.

In all the double inoculation experiments only half of the biomass of each strain was added to the microcosm, so degradation levels corresponding to the arithmetic mean of the two singular strains were expected. However, in the examples shown in this work, when the microcosms received both strains, the final levels of organic removal in the presence of a heavy metal were well above the ones anticipated. When Cd was used, the expected degradation values of MTBE for pairs VF3 ? PM1 and VF7 ? VF3 were exceeded by 182 and $142 \%$, respectively (Fig. 1a, b). In the case of $\mathrm{Hg}$, pairs VF7 ? F5.4 and VF5 ? F5.4 exceeded the expected values by 97 and $107 \%$, respectively (Fig. 1c, d). When $\mathrm{Pb}$ was present, the strain pairs chosen were VF5 ? EHg5 or VF7 ? EHg5. In these cases the degradation levels were 122 and $158 \%$ higher than the predicted values (Fig. 1e, f).

\section{TCE degradation tests}

In the case of $\mathrm{TCE}$, strains $\mathrm{Mil}$ and $\mathrm{EHg} 7$ were selected as degraders, while strains VF3, F5.4 and EHg5 were chosen as resistant members of the pairs (VF3 for $\mathrm{Cd}$; F5.4 for $\mathrm{Hg}$; $\mathrm{EHg} 5$ for $\mathrm{Pb}$ ). In the instances shown, when the microcosms were inoculated with two strains, clearly a synergistic effect was observed since the double inoculation yielded values of organic removal well higher than the expected levels: strains Mi1 ? VF3 (?Cd) caused the disappearance of $103 \%$ more TCE than the expected mean between the two strains taken singularly; EHg7 ? F5.4 (? $\mathrm{Hg})$ exceeded the predicted value by $49 \%$; Mi1 ? EHg5 (?Pb) together outdid the anticipated level by $57 \%$.

\section{Discussion}

Remediation of sites co-contaminated with organics and heavy metals can be very difficult due to the inhibiting effect that toxic metals exert on the microflora (Sandrin and Maier 2003). A few works have demonstrated that in principle it is possible to alleviate some of the inhibition caused by heavy metals by employing metal-resistant microorganisms that, each in its own way, somehow lessen the toxic burden of the metal ions (Roane et al. 2001; Je'zéquel et al. 2005). In most cases these microorganisms will lower bioavailability of the metals by sequestering the ions on extracellular anionic polysaccharides 
(EPS) or on thiol-rich proteins (either intracellular or anchored to the cell surface). In some cases, such type of trait was deliberately engineered in microbial cells (Kuroda et al. 2001; Lee et al. 2006).

In this work we isolated and selected several bacterial strains capable of withstanding considerable concentrations of $\mathrm{Cd}^{2 ?}$ or $\mathrm{Hg}^{2}$ or $\mathrm{Pb}^{2 ?}$ and coupled them with strains that showed good performance at degrading the common soil and water pollutants MTBE or TCE. Some of the combinations of strains we examined showed microcosm degradation efficiencies frankly higher than those expected on the grounds of a purely additive interaction: between 49 and $103 \%$ higher for TCE and between 97 and 182\% for MTBE. This demonstrates that synergy between the members of these consortia is indeed occurring, resulting in a cooperative effect. Since many sites are polluted with both organic and inorganic contaminants, several works have explored the possibility of obtaining metal-resistant organic-degrading microorganisms. However, such microbes are difficult to recover by enrichment techniques and attempts have been made to introduce metal resistance traits in natural degrading strains by genetic engineering. The idea of dual bioaugmentation (Roane et al. 2001) resides in the usage of two separate microbial species, each with its separate task of detoxifying the heavy metal on the one hand and degrading the organic pollutant on the other. We applied this design to soil microcosms and showed that dual bioaugmentation, even without making use of genetically modified microrganisms, are a viable option for the remediation of soils polluted with MTBE or TCE and heavy metals.

Acknowledgments We wish to acknowledge funding form the Portuguese Science and Technology Foundation, research project AMB/57353/2004 and personal grant to PDM SFRH/ BPD/20577/2004 funded by POCI2010, co-funded by FEDER. We would like to thank Pedro Moradas-Ferreira, Catarina Pacheco, Ricardo Hugo Pires (IBMC), Ana Rita Carvalho and Etelvina Figueira (University of Aveiro) for their support.

\section{References}

Achten C, Püttmann W (2001) Method for determination of methyl tert-butyl ether in gasoline by gas chromatography. J Chromatogr A 910:377-383. doi:10.1016/S00219673(00)01220-6

Adebusoye SA, Picardal FW, Ilori MO, Amund OO, Fuqua C, Grindle N (2007) Aerobic degradation of di- and trichlorobenzenes by two bacteria isolated from polluted tropical soils. Chemosphere 66:1939-1946. doi:10.1016/ j.chemosphere.2006.07.074

ATSDR (2003) - Agency for Toxic Substances \& Disease Registry, Department of Health and Human Services, USA. http://www.atsdr.cdc.gov/NER/tce.html

Aulenta F, Bianchi A, Majone M, Papini MP, Potalivo M, Tandoi V (2005) Assessment of natural or enhanced in situ bioremediation at a chlorinated solvent-contaminated aquifer in Italy: a microcosm study. Environ Int 31:185190. doi:10.1016/j.envint.2004.09.014

Bowman JP, Jimenez L, Rosario I, Hazen TC, Sayler GS (1993) Characterization of the methanotrophic bacterial community present in the tricholoroethylene-contaminated subsurface groundwater site. Appl Environ Microbiol 59:2380-2387

Brusseau GA, Tsien H-C, Hanson RS, Wackett LP (1990) Optimization of trichloroethylene oxidation by methanotrophs and the use of a colorimetric assay to detect soluble methane monooxygenase activity. Biodegradation 1:19 29. doi:10.1007/BF00117048

Commission of the European Communities (1986) Council directive on the protection of the environment, and in particular of the soil, when sewage sludge is used in agriculture. Off J Eur Communities L181 Annex 1A:10

De Marco P, Pacheco CC, Figueiredo AR, Moradas-Ferreira P (2004) Novel pollutant-resistant methylotrophic bacteria for use in bioremediation. FEMS Microbiol Lett 234:75-80

DiSpirito AA, Gulledge J, Shiemke AK, Murrell JC, Lidstrom ME, Krema CL (1991) Trichloroethylene oxidation by the membrane-associated methane monooxygenase in type I, type II and type X methanotrophs. Biodegradation 2:151164. doi:10.1007/BF00124489

Fayolle F, Franc, ois A, Garnier L, Godefroy D, Mathis H, Piveteau P, Monot F (2003) Limitations in MTBE biodegradation. Oil Gas Sci Technol 58:497-504. doi: 10.2516/ogst:2003033

Jézéquel K, Perrin J, Lebeau T (2005) Bioaugmentation with Bacillus sp. to reduce the phytoavailable $\mathrm{Cd}$ of an agricultural soil: comparison of free and immobilized microbial inocula. Chemosphere 59:1323-1331. doi: 10.1016/j.chemosphere.2004.11.050

Kalyuzhnaya MG, De Marco P, Bowerman S, Pacheco CC, Lara JC, Lidstrom ME, Chistoserdova L (2006) Methyloversatilis universalis, gen. nov., sp. nov., a new taxon within the Betaproteobacteria represented by three methylotrophic isolates. Int $\mathrm{J}$ Syst Evol Microbiol 56:2517-2522. doi:10.1099/ijs.0.64422-0

Kelly DP, Baker SC, Trickett J, Davey M, Murrell JC (1994) Methanesulphonate utilization by a novel methylotrophic bacterium involves an unusual monooxygenase. Microbiology 140:1419-1426

Kuroda K, Shibasaki S, Ueda M, Tanaka A (2001) Cell surface-engineered yeast displaying a histidine oligopeptide (hexa-His) has enhanced adsorption of and tolerance to heavy metal ions. Appl Microbiol Biotechnol 57:697-701. doi: $10.1007 / \mathrm{s} 002530100813$

Lane DJ (1991) 16S/23S rRNA sequencing. In: Stackebrandt E, Goodfellow M (eds) Nucleic acid techniques in bacterial systematics. Wiley, New York, pp 115-175

Lee W, Wood TK, Chen W (2006) Engineering TCE-degrading rhizobacteria for heavy metal accumulation and 
enhanced TCE degradation. Biotechnol Bioeng 95(3): 399-403. doi:10.1002/bit.20950

Olaniran A, Pillay D, Pillay B (2006) Biostimulation and biaugmentation enhances aerobic biodegradation of dichloroethenes. Chemosphere 63:600-608. doi:10.1016/ j.chemosphere.2005.08.027

Roane TM, Josephson KL, Pepper IL (2001) Dual-biaugmentation strategy to enhance remediation of cocontaminated soil. Appl Environ Microbiol 67:3208-3215. doi:10.1128/ AEM.67.7.3208-3215.2001

Sandrin TR, Maier RM (2003) Impact of metals on the biodegradation of organic pollutants. Environ Health Perspect 111:1093-1101
Shields MS, Reagin MJ, Gerger RR, Campbell R, Somerville C (1995) TOM, a new aromatic degradative plasmid from Burkholderia (Pseudomonas) cepacia G4. Appl Environ Microbiol 61:1352-1356

USEPA (1997) Drinking water advisory: consumer acceptability advice and health effects analysis on methyl tertiary butyl ether (MTBE). EPA/822/F-97/008. December 1997. Office of water, Washington, DC, USA 